\title{
Risk factors of long-term sickness absence in Norway and Sweden
}

\author{
Vegard Johansen \\ Eastern Norway Research Institute \\ Email: vj@ostforsk.no
}

\begin{abstract}
Aims: This paper examines the level of long-term sickness absence (LTSA) in Norway and Sweden. It also investigates whether risk factors of LTSA are the same in Norway and Sweden.

Methods: More than 2500 Norwegian and Swedish workers between 20 and 60 years of age answered a postal questionnaire. The Norwegian and Swedish samples are weighted and representative with regard to regional background variables and demographic background variables, but the response rate was low. LTSA is defined as 15 days or more sickness absence in the previous year. Binary logistic regression is used to detect which factors influence LTSA. The analyses of LTSA include demographic factors, socioeconomic position, and occupational characteristics.

Results: Nineteen per cent of respondents in Norway and 11 per cent of respondents in Sweden experienced LTSA in the previous year. Many respondents from Sweden report mental problems and many Norwegian respondents report pain in back, neck, knuckles, and muscles. Income level is the most important predictor of LTSA in both countries. The direct impacts of gender, age, and physical work conditions are stronger in Norway than Sweden.

Discussion: In accordance with official statistics and previous studies, the proportion of Norwegian respondents with LTSA is much higher than the proportion of Swedish respondents. The different levels of LTSA could be linked to differences in social policy. In line with previous studies, respondents with low income are overrepresented with LTSA, and gender, age, and physical work also matter. In contrast to previous studies, there is not any evidence of higher levels of LTSA among non-western immigrants, people with less education, and non-managers. These results reflect the control for 'income level', but they could also be related to limits with the survey (nonresponse, response bias, etc.).
\end{abstract}

Keywords: Long-term sickness absence, risk factors, survey, Norway, Sweden, logistic regression 


\section{Introduction}

This article discusses long-term sickness absence (LTSA) in Norway and Sweden. There are many studies on sickness absence and LTSA (Lidwall, 2010), but fewer studies with a comparative approach. Comparative studies can potentially contribute to the knowledge about societal, cultural and legislative effects on outcomes such as LTSA. The two countries examined may look alike from distance: Norway and Sweden are neighbours, exchange labour extensively, and have robust job protection, high levels of work participation, and healthy populations (Bonato \& Lusinyan, 2004; Markussen, 2007). Both countries are vast welfare states, but sickness benefits in Norway are more generous than they are in Sweden: a sick-listed person in Norway receives full compensation of the loss of income from the first day for a maximum of 364 days, whilst in Sweden the employees themselves pay for the starting day and receive 80 per cent compensation of the loss of income for a maximum of 364 days within a frame of 450 days (Government proposition no.136, 2008; Ministry of Labour and Social Inclusion, 2011). Moreover, the level of sickness absence is much higher in Norway compared with Sweden (Berge, 2012). In the last decade, the mean rate of doctorcertified sickness absence in Norway was more than six per cent and four per cent in Sweden (Statistics Norway 2013; Statistics Sweden, 2013). Moreover, a survey a few years ago provided indications of profound differences between respondents from the two countries in attitudes towards sickness absence (Dahl et al., 2007).

This article examines the level of LTSA in Norway and Sweden, and investigates whether a selection of risk factors of LTSA are the same in Norway and Sweden. The investigation of risk factors of LTSA includes demographic factors, socio-economic position, and occupational characteristics. There are two reasons for focusing on LTSA and not sickness absence in general. First, short-term sickness absence does not require sickness certification from a doctor, and it is therefore often used to respond to common and minor problems. Secondly, workers with LTSA account for much of the total sickness absence in both countries, and they must be the target group for a reduction of the total levels to take place (Mykletun et al., 2007). The data is from a questionnaire answered by more than 2500 Norwegian and Swedish workers between 20 and 60 years of age.

\section{Scandinavian studies of LTSA}

The high levels of sickness absence and LTSA in Norway and Sweden constitute an important research topic from both a public-health and an economic perspective. Sickness absence is caused by a variety of factors. Since labour-market conditions and social conditions vary, who is at risk of LTSA may vary significantly from country to country. Therefore, I shall now discuss the factors that previous Scandinavian studies of LTSA have found to be relevant.

First, a review of sickness absence in Norway discusses many factors relevant to LTSA (Ose, 2010). It is shown that women run a higher risk of LTSA than men. Several hypotheses have been put forward to explain gender differences with regard to LTSA, such as women's reproductive role, women's responsibilities for the family, and the fact that men and women have different working conditions. Income is an important measure of socio-economic 
position, and there is a strong and negative correlation between income and LTSA. Moreover, the review also refers to cross-country studies that have shown that sickness benefits have a robust and positive impact on absence. The association between economic incentives in the social-insurance system and sickness absence is also found in Swedish studies (Andren, 2005).

Secondly, a Swedish study of changes over time in factors associated with LTSA used data from studies conducted in 1992 (2600 respondents) and 2002 (3900 respondents). The results showed that both weak social support and high ergonomic exposure had consistent influence on LTSA, whilst having a high-strain job was associated with LTSA in 2002 but not in 1992. In 2002, women ran a higher risk of LTSA than men, but not in 1992. For the women, daily smoking, being overweight, permanent employment, public employment, active jobs, and working more than 45 hours a week were all associated with LTSA in the 2002 study, but not in the 1992 study. Age and education seem to matter for LTSA, whilst the family situation had less influence (Lidwall et al., 2009).

Thirdly, a Danish study with more than 5000 respondents identified that higher risks of LTSA was associated with gender, age, educational level, the municipal employment sector, and work-environment exposures, such as ergonomic conditions and physically demanding work. Uncomfortable working positions, lifting or carrying loads, and pushing or pulling loads are factors increasing the risk of LTSA. Moreover, LTSA among females was associated with role conflict, low reward, and poor management, whilst high emotional demands predicted LTSA among men (Lund et al., 2006; 2007). The association between physical working conditions and sickness absence is also found in a study among employees in the Swedish public sector, and this study also indicates interactions between ergonomic working conditions and the psychosocial work environment (Fjell et al., 2007). Substantial attention has also been paid to psychosocial conditions in the workplace and sickness absence, and the relation between health and the psychosocial work environment has been well illustrated by the demand-control model (Karasek \& Theorell, 1990).

Fourthly, 15 per cent of the Swedish population and nine per cent of the Norwegian population are immigrants. Non-western immigrants have poorer health than others, and in many European countries non-western immigrants are characterized by low employment rates and precarious employment in low-paid jobs. Swedish studies have shown that there are differences in sickness absence among natives and non-western immigrants (Nilsson, 2005; Bengtsson \& Scott, 2006). Similarly, a Norwegian study concludes that absence rates are higher among some groups of non-western immigrants than among ethnic Norwegians: after controlling for demographic factors, labourmarket factors, and socio-economic differences, workers from Africa and Asia (men) still have higher propensity for LTSA (Dahl et al., 2010).

Fifthly, position at the workplace and type of work might also have an impact on LTSA. In Norway, self-employed men seem to have lower sicknessabsence levels compared with employed men, but self-employed women had higher sickness absence levels compared with employed women (Nossen \& Thune, 2010). In Sweden, a study indicates vast differences between employees with and without managerial responsibilities with regard to sickness absence: managers have less sickness absence periods compared with other 
groups of employees (Mulder, 2011). Type of occupation matters to LTSA, and one might distinguish between different occupational classes with divergent levels of LTSA, such as white collar, blue collar, self-employed, and so on (Lidwall, 2010).

Sixthly, various studies have investigated relations between socio-economic position and sickness absence, and have found that people with less education face a higher risk of LTSA than those highly educated do (Labriola et al., 2007). Similarly, those with low income are overrepresented among those with high levels of sickness absence (Ose, 2010). There is also a growing literature on the effects of family relations and sickness absence. Some studies indicate that workers struggling to combine their work and family life have a higher risk of LTSA (Lidwall, 2010), whilst other studies do not find such correlations (Lidwall et al., 2009). Cohabitation and the presence of children may constitute higher demands at home (for women), and sickness absence could be an adverse outcome of this double work-home burden. In particular, single parenthood is associated with sickness absence.

Finally, there are also studies that have looked into the association between lifestyle factors and LTSA. Following a nation-wide cohort of more than 40000 Swedish men between 1986 and 2005 regarding sick-leave, it was found that lifestyle factors such as being overweight or obesity influenced LTSA (Neovious et al., 2012). Using data from three cross-sectional samples of the working population, another Swedish study examined work-related sleep disturbances and their association with LTSA (Westerlund et al., 2008). In a Swedish study with 1700 respondents between 20 and 52 years, a consistent pattern of increased sickness absence was seen for high consumers and for those with indications of a drinking problem (Upmark et al., 1999).

\section{Method}

This study uses data from a survey in Norway and Sweden from 2011. The data collection took two months; it began in the beginning of March and ended in the beginning of May. The data collection was funded by the Research Council of Norway. The Research Council of Norway had no role in the following: study design; the collection, analysis and interpretation of the data; in the writing of the article; and the decision to submit for publication. The research was done in accordance with the rules set by the committees for medical research ethics in both Norway and Sweden, and it was approved by the Norwegian Social Science Data Services.

In both countries, the process of selecting the gross sample was simple random sampling from the population of workers between 20 and 60 years of age. The net samples included 1600 Norwegians and 1250 Swedes. The data are weighed according to country of origin, so that the Norwegian and Swedish samples have the same influence.

The response rate was low (33 per cent in both countries), but this is similar to other levels of living surveys in Norway and Sweden. Response rates tend to be very low for postal questionnaires (Edwards et al., 2002), but it was the only financially viable option for this cross-country study. To increase the response rate, the length of the questionnaire was kept quite short (four pages and 60 questions), a postal follow-up including questionnaire was sent, the 
return envelope was pre-paid, and the information letter stressed the benefits of the study to society.

To test for non-response bias, known values from the population of workers between 20 and 60 years of age and the potential participants were compared with the values that prevail in the subgroup that answered the questionnaire. It is positive that the Norwegian and Swedish net samples were representative with regard to ethnic background, as well as representative of regional dimensions like the size of municipality, county, and centrality/peripherality. The Norwegian net sample is representative with regard to gender, whilst there is an overrepresentation of women in the Swedish sample. In the net samples for Norway and Sweden, those in the age group 40-60 are overrepresented and those between 20 to 39 years are underrepresented. The data were weighed according to age and gender in order to remedy the underrepresentation of young workers and men.

Questions about work, including sickness absence, were answered by 2533 respondents who were either working, on parental leave, or on leave of absence. There are five basic ways of assessing sickness absence: frequency refers to sickness absence episodes, incidence rate refers to estimates of frequency per person-time, duration refers to mean or median days spent away during each episode of sickness absence, length is often measured as number of days of sickness absence, and cumulative incidence is used to assess the proportion of individuals absent during a specified period (Hensing, 2009). The chosen question was formulated like this: 'How many days did you take sick leave the last 12 months?' It allows for an investigation of the proportion of individuals with sickness absence in the prior year (cumulative incidence) and the distribution of absent days per worker (length). Respondents were given six alternatives: 0 days, 1-7 days, 8-14 days, 15-30 days, 31-90 days, and 91-365 days. LTSA is a phenomenon defined very differently in the literature, and a review of the literature reveals that cut-off points such as seven days (Kivimäki et al., 2003), 15 days (Lidwall et al., 2009), 28 days (Vingård et al., 2005), 56 days (Lund et al., 2007), 60 days, and 90 days (Lidwall, 2010) are used. The choice of cut-off point seems to be rather arbitrary, and divergent cut-off points also pose a problem for comparisons between studies: it is unreasonable to match up studies referring to LTSA as seven days and those referring to three months. The current study defines LTSA as 15 days or more. The available data also allows sensitivity analysis, and this defines LTSA as 31 days or more.

Answers to questions about the past can be imperfect and thereby affect the validity of the results of the survey. Ninety-eight per cent of the potential respondents answered the question about sickness absence in the prior year. It could be that the choice of six alternatives (closed question) made it easier to answer about sickness absence than it would have been if the respondents were asked to remember the exact number of days (open question). It is, however, hard to make conclusions about the accuracy of their answers.

Response bias refers to instances when a respondent intentionally responds incorrectly to a question about their personal history. Some former studies have shown that employees tend to under-report their sickness absence (van Poppel et al., 2002). This study does not control for over- or underreporting with regard to LTSA. It must be noted, though, that response bias is particularly problematic with interviews face-to-face or over the phone; there is 
less of an interview effect in this study, where respondents wrote down their answers in an anonymous survey.

Binary logistic regression has been used to detect which factors influence LTSA. Binary logistic regression is suitable for predicting the outcome of a categorical criterion variable that can take on only two possible outcomes. Nagelkerke $R^{2}$ indicates how accurate the models are in terms of how much of the total variation the factors included in the model are able to explain. The independent variables include demographic characteristics, socio-economic position, and work-related factors.

- Gender: male (reference category, 50 per cent of the sample) and female (50 per cent);

- Age in years;

- Ethnic background: divided between natives and western immigrants (comprising Western Europe, Canada, USA, Australia, and New Zealand (reference category, 94 per cent of the sample), and nonwestern immigrants (comprising persons born in other countries, six per cent);

- Education: divided between high educational attainment (Bachelor degree or higher, 36 per cent of the sample) (reference category) and low educational attainment (64 per cent);

- Income: divided between low income (0-299,000 NOK/SEK, 40 per cent of the sample), and medium income $(300,000-499,000$ SEK/NOK, 43 per cent), and high income $(500,000+$ NOK/SEK, 17 per cent);

- Type of employment: divided between employee in the public sector (reference category, 37 per cent), employee in the private sector (51 per cent) and self-employee (12 per cent);

- Employment position: divided between those that do not have a managerial position (reference category, 71 per cent of the sample), and middle management/executives (29 per cent).

Although the models for LTSA in Norway and Sweden are quite complex, they still consist of a limited selection of potential risk factors. Important factors are missing that could have changed the results. Most significantly, I do not have information about respondents' health, which is arguably an important determinant of LTSA. There is also extensive research on the relationship between the psycho-social conditions in working life and sickness absence, but the data does not cover that topic. In addition, I cannot investigate the possible correlations between lifestyle factors and LTSA.

\section{Results}

I begin with a descriptive analysis of LTSA in the two samples. According to table 1, 21 per cent of the Norwegian sample and 11 per cent of the Swedish sample experienced LTSA ( 15 days or more sickness absence). Using a more narrow definition (31 days or more sickness absence), I have found that 12 per cent of the Norwegian sample and six per cent of the Swedish sample had LTSA. On a minor note, a higher proportion of respondents in Norway than Sweden did not experience any sickness absence (53 per cent versus 46 per cent). If we use the narrow definition of LTSA (31 days or more), the main 
cause for the Norwegian sample is pain in back, neck, knuckles, and muscles, and the Swedish sample most often reported mental problems (25 per cent) and injury/accident (21 per cent).

Table 1. Distribution of sickness absence in Norway and Sweden, in percentage

\begin{tabular}{lll}
\hline & Norway & Sweden \\
\hline 0 days & 53 & 46 \\
$1-7$ days & 21 & 35 \\
$8-14$ days & 7 & 8 \\
$15-30$ days & 7 & 5 \\
$31-90$ days & 6 & 3 \\
$91-365$ days & 6 & 3 \\
Sum & 100 & 100 \\
\hline
\end{tabular}

Table 2 and table 3 presents the unstandardized coefficients and $p$-values from regression analyses of LTSA in Norway and Sweden. In Table 2 LTSA is defined as 15 days or more sickness absence. There are statistically significant effects for 'low income' and 'medium income' in both Norway and Sweden. In the Norwegian model, 'female', 'age', and 'physical work' are also significant. In the Swedish model, a closer examination shows that gender for the most part has an indirect effect on LTSA: women are overrepresented in the category 'low income', which in turn affects LTSA. The remaining variables are non-significant.

Table 2. Binary logistic regression of the factors influencing SP in Norway and Sweden, LTSA defined as $\mathbf{1 5}$ days or more.

\begin{tabular}{lllll}
\hline Variables & \multicolumn{2}{c}{ Norway } & \multicolumn{2}{c}{ Sweden } \\
\hline \multirow{2}{*}{ Constant } & $\mathrm{B}$ & $\mathrm{OR}$ & $\mathrm{B}$ & $\mathrm{OR}$ \\
Female & $-3.56^{\star *}$ & 0.03 & $-3.60^{\star *}$ & 0.03 \\
Age & $0.48^{\star \star}$ & 1.61 & -0.07 & 0.94 \\
Non-western immigrant & $0.014^{\star}$ & 1.01 & 0.00 & 1.00 \\
Low education & -0.03 & 0.97 & -0.05 & 0.95 \\
Low income & 0.25 & 1.28 & 0.23 & 1.34 \\
Medium income & $1.04^{\star \star}$ & 2.84 & $1.95^{\star \star}$ & 6.99 \\
Self-employed & $0.70^{\star *}$ & 2.02 & $1.03^{\star}$ & 2.80 \\
Employee in private sector & -0.20 & 0.82 & -0.23 & 0.79 \\
Management & 0.31 & 1.36 & -0.17 & 0.84 \\
Physical work & -0.14 & 0.86 & -0.08 & 0.92 \\
\hline
\end{tabular}

${ }^{* *}=$ Significant at $0.01,{ }^{*}=$ Significant at 0.05

Reference categories: male; native or western immigrant; high education; high income; employee in public sector; non-management; sedentary work

Nagelkerke $R^{2}: 0.10$ (Norway) and 0.06 (Sweden) 
Table 3. Binary logistic regression of the factors influencing SP in Norway and Sweden, LTSA defined as $\mathbf{3 1}$ days or more.

\begin{tabular}{lllll}
\hline Variables & \multicolumn{2}{c}{ Norway } & \multicolumn{2}{c}{ Sweden } \\
\hline & $\mathrm{B}$ & $\mathrm{OR}$ & $\mathrm{B}$ & $\mathrm{OR}$ \\
Constant & $-3.82^{\star *}$ & 0.02 & $-3.67^{\star *}$ & 0.03 \\
Female & 0.32 & 1.38 & -0.09 & 0.91 \\
Age & 0.011 & 1.01 & 0.006 & 1.01 \\
Non-western immigrant & -0.62 & 0.54 & -0.37 & 0.69 \\
Low education & 0.27 & 1.31 & 0.22 & 1.25 \\
Low income & $1.16^{\star *}$ & 3.19 & $1.45^{\star}$ & 4.25 \\
Medium income & $0.65^{\star *}$ & 1.92 & 0.17 & 1.19 \\
Self-employed & -0.12 & 0.89 & -0.49 & 0.61 \\
Employee in private sector & 0.32 & 1.37 & -0.42 & 0.66 \\
Management & -0.15 & 0.86 & -0.02 & 0.98 \\
Physical work & $0.49^{\star}$ & 1.63 & -0.20 & 0.82 \\
\hline
\end{tabular}

${ }^{\star \star}=$ Significant at $0.01,{ }^{*}=$ Significant at 0.05

Reference categories: male; native or western immigrant; high education; high income; employee in public sector; non-management; sedentary work

Nagelkerke $R^{2}: 0.07$ (Norway) and 0.06 (Sweden)

In most cases, the results in table 3 are parallel to those in table 2. When LTSA is defined as 31 days or more, there are statistical significant effects for 'low income' and 'medium income'. Whilst physical work is significant in the Norwegian model, neither 'female' nor 'age' is significant. This illustrates the importance of the choice of cut-off point.

\section{Discussion}

Tables 1-3 have shown similarities and differences in LTSA in Norway and Sweden. A major difference is that the level of LTSA is twice as high in Norway as in Sweden. A second difference concerns the causes for LTSA: many respondents from Sweden report mental problems and many Norwegian respondents report pain in back, neck, knuckles, and muscles. This finding reflects the national statistics: musculoskeletal problems are the most typical diagnoses in Norway, and mental problems are the most typical diagnoses in Sweden.

Norway and Sweden should be comparable nations with regard to the health situation, and the different levels of LTSA could be linked to differences in social policy. The structure and administration of the sickness-insurance scheme in each country is a fundamental factor affecting LTSA. Previous cross-country studies have shown that sickness benefits have a robust and positive impact on absence (Bonato \& Lusinyan, 2004; Ose, 2010), and the association between economic incentives in the sickness-insurance scheme is particularly strong with regard to 'shorter' sickness absence (Andren, 2005; Lidwall, 2010). It seems plausible to interpret part of the cross-country difference in LTSA as a result of the more generous sickness benefits in Norway.

Another reason for differences in LTSA could be that the Swedish labour market is in a tougher situation than the Norwegian labour market: Sweden has higher unemployment rates and is more affected by the European sovereign-debt crisis than Norway. An earlier Swedish study indicates that the 
rate of sickness absence decreases in times of recession and increases during economic prosperity (Lidwall \& Marklund, 2011). The idea of an association between increased unemployment and decreased sickness absence is based on the notion that employees have less absence because they are afraid of losing their jobs if they are absent too often, and that people with extensive absence are designated to unemployment (Shapiro \& Stiglitz, 1984; Leigh, 1985). Some of the decline in sickness absence in Sweden in the past decade could also be credited the development of tighter standards for sick leave at different diagnoses (Mykletun et al., 2010).

Most results regarding risk factors for LTSA are the same in Norway and Sweden. Level of income is the most important predictor for LTSA in both countries, and the strong correlation between low income and high level of LTSA is also found in previous studies (Ose, 2010). In both countries, the impact of educational level was less strong than expected. An important reason for the low impact of education on LTSA is the adjustment for income level and managerial position. Former studies conclude that rates of absence are higher among non-western immigrants than among natives (Nilsson, 2005; Bengtsson \& Scott, 2006; Dahl et al., 2010), but significant correlations are not found in this study. There are few non-western immigrants in the sample. Also, non-western immigrants are overrepresented with short-term absence in both countries, and this is not covered in the discussion about LTSA.

There are no significant effects for type of employment or employment position. The data includes few respondents that are executive managers, and so middle managers were included in the managerial group. This partly explains the missing correlation, but the most important factor is the control for level of income. With regard to type of employment, a closer investigation of the data shows that self-employed women have higher LTSA compared with employed women, but that self-employed men have lower LTSA compared with employed men. This finding is parallel to Nossen and Thune's result (2010).

Some results differ between the two countries. The direct impact of gender is strong in Norway, but less strong in Sweden. In Sweden, gender has more of an indirect impact: gender affects income which in turn affects LTSA. Age also seem to have stronger direct impact in Norway than in Sweden. The reason for expecting a higher rate of sickness absence from the older part of the workforce is that people will accumulate health problems during their (working) life and that they get tired and exhausted. LTSA is more frequent for the elderly part of the job stock than the younger in Norway. Also, a high physical workload increases the risk of LTSA in Norway, but not in Sweden. The impact of physical work conditions on LTSA has also previously been documented in Danish studies (Lund et al., 2006; 2007).

\section{Final comments}

In Norway and Sweden, a small group of workers with LTSA account for most of the total sickness absence. The identification of risk factors of LTSA is therefore necessary for the choice of correct policies for the reduction of the total level of sickness absence. Because this study used self-reported and cross-sectional data, the results are tentative. 
The main strength and contribution of this article is that it compares LTSA between workers in Norway and Sweden, and this is something that few studies have done before. A major difference between Norway and Sweden is the proportion of workers with LTSA: 19 per cent of the Norwegian respondents compared with 11 per cent of the Swedes experienced 15 or more days of absence in the previous year. With regard to risk factors for LTSA, the direct impacts of gender, age, and physical work conditions are stronger in Norway than Sweden. Still, income level is the most important predictor of LTSA in both countries.

In contrast to previous studies, there is not any evidence of higher levels of LTSA among non-western immigrants, people with less education, and nonmanagers. A main reason for the divergent results could be that the current study controls for the impact of income level, a variable that correlate strongly with ethnic background, education, and position. Still, given that previous studies use population data from public registers, one could argue that the results in this study are less reliable. There are four potential reasons that might explain why this study has not found statistical effects with regard to ethnic background, education, and employment position: i) the classification of groups is broader in this study than in the previous studies (e.g., executives and managers together); ii) some groups of respondents are quite small (e.g., non-western immigrants); iii) the response rate was low and that could affect survey accuracy; and iv) there might be problems with recall bias and response bias.

\section{References}

Andren, D. (2005). 'Never on a Sunday': Economic incentives and short-term sick leave in Sweden. Applied Economics, 37(3), 327-338.

Bengtsson, T. \& Scott, K. (2006). Immigrant consumption of sickness benefits in Sweden, 1982-1991. Journal of Socio-Economics, 35(3), 440-457.

Berge, C. (2012). Internasjonal sammenligning av sykefravær [International comparison of sickness absence]. Økonomiske analyser, (2), 24-29.

Bonato L. \& Lusinyan, L. (2004). Work absence in Europe. Report, International Monetary Fund, Washington.

Dahl, S.Å., Holmås, T.H., Skjeret, F. (2007). En kartlegging av holdninger til sykefravær i Norden [Attitudes towards sickness absence in the Nordic countries]. Oslo: Institute for Research in Economics and Business Administration.

Dahl, S.V., Hansen, H.T. \& Olsen, K.M. (2010). Sickness absence among immigrants in Norway, 1992-2003. Acta Sociologica, 53(1), 35-52.

Edwards, P., Roberts, I., Clarke, M., DiGuiseppi, C., Pratap, S., Reinhard, W. \& Kwan, I. (2002). Increasing response rates to postal questionnaires: systematic review. BMJ, 324, 1-9.

Fjell, Y., Alexanderson, K., Karlqvist, L. \& Bildt, C. (2007). Self-reported musculoskeletal pain and working conditions among employees in the Swedish public sector. Work 28(1), 33-46.

Government proposition no.136. (2008). En reformerad sjukskrivningsprocess för ökad återgång $\mathrm{i}$ arbete [A reformed sick leave for increased return to work]. Stockholm: Ministry of health and social affairs. 
Karasek, R. \& Theorell, T. (1990). Healthy work: Stress, productivity and the reconstruction of working life. New York: Basic Books.

Kivimäki, M., Head, J., Ferrie, J.E., Shipley, M.J., Vahtera, J. \& Marmot, M.G. (2003). Sickness absence as a global measure of health: evidence from mortality in the Whitehall II prospective cohort study. BMJ, 327, 364-368.

Labriola, M., Lund, T. \& Christensen, K.B. (2007). Resultater av sygefraværsforskning 2003-2007 [Results of sickness-absence research 2003-2007]. Report, National Research Centre for the Working Environment, Copenhagen.

Leigh, J.P. (1985). The effects of unemployment and the business cycle on absenteeism. Journal of Economics and Business, 37(2), 159-170.

Lidwall, U. (2010). Long-term sickness absence: aspects of society, work and family. $\mathrm{PhD}$ Thesis, Stockholm University, Sweden.

Lidwall, U., Bergendorff, S., Voss, M. \& Marklund, S. (2009). Long-term sickness absence: changes in risk factors and the population at risk. International Journal of Occupational Medicine and Environmental Health, 22(2), 157-168.

Lidwall, U. \& Marklund, S. (2011). Trends in long-term sickness absence in Sweden 1992-2008: the role of economic conditions, legislation, demography, work environment and alcohol consumption. International Journal of Social Welfare, 20(2), 167-179.

Lidwall, U., Marklund, S. \& Voss, M. (2009). Work-family interference and long-term sickness absence: a longitudinal cohort study. European Journal of Public Health, 20(6), 676-681.

Lund, T., Labriola, M., Christensen, K.B. et al. (2006). Physical work environment risk factors for long term sickness absence: prospective findings among a cohort of 5357 employees in Denmark. BMJ, 332, 449-452.

Lund, T., Labriola, M. \& Villadsen, E. (2007). Who is at risk for long-term sickness absence? A prospective cohort study of Danish employees. Work, 28(3), 225230.

Markussen, S. (2007). Økonomisk sykefraværsforskning: Hva vet vi, og hvor bør vi gå? [Economic sickness absence: what do we know, and where should we go?] Søkelys på arbeidslivet, 24(1), 63-81

Ministry of Labour and Social Inclusion (2011). The Norwegian Social insurance scheme 2011. Oslo: Ministry of labour and social inclusion.

Mulder, M. (2011). Sjukskrivningsdiagnoser i olika yrken [Sick-listing diagnoses in different occupations]. Report, The Swedish Social Insurance Agency, Stockholm.

Mykletun, A., Eriksen, H.R., Røed, K. et al. (2010). Tiltak for reduksjon i sykefravær: Aktiviserings-og nærværsreform [Measure for the reduction of sickness absence: activating and presence reform]. Report for the Ministry of labour and social inclusion, Oslo.

Neovius, K., Neovius, M., Kark, M. \& Rasmussen, F. (2012). Association between obesity status and sick-leave in Swedish men: nationwide cohort study. European Journal of Public Health, 22(1), 112-116.

Nilsson, M. (2005). Differences and similarities in work absence behaviour. Empirical analyses of micro panel data. PhD Thesis, Växjö University, Växjö. 
Nossen, J.P. \& Thune, O. (2010). Sykefravær blant selvstendig næringsdrivende - er nivå og utvikling forskjellig fra lønnstakerne? [Sickness absence among the selfemployed: are the levels and development different from those of wageearners?] Arbeid og velferd, (2), 60-67.

Ose, S.O. (2010). Kunnskap om sykefravær: nye norske bidrag [Knowledge on sickness absence: new Norwegian contributions]. Report, SINTEF, Trondheim.

Shapiro, C. \& Stiglitz, J.E. (1984). Equilibrium unemployment as a worker discipline device. The American Economic Review, 74(3), 433-444.

Statistics Norway (2013). Working conditions, sickness absenteeism. http://www.ssb.no/english/subjects/06/02/

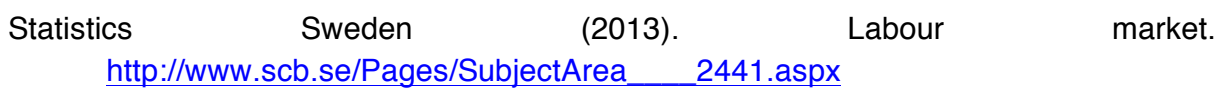

Upmark, M., Möller, J. \& Romelsjö, A. (1999). Longitudinal, population-based study of self-reported alcohol habits, high levels of sickness absence, and disability pensions. Journal of Epidemiology and Community Health, 53(4), 223-229.

van Poppel, M. N., de Vet, H., Koes, B. W. et al. (2002). Measuring sick leave: a comparison of self-reported data on sick leave and data from company records. Occupational Medicine, 52(8), 485-490.

Vingård, E., Lindberg, P., Josephson, M. et al. (2005). Long-term sick-listing among women in the public sector and its associations with age, social situation, lifestyle, and work factors: A three-year follow-up study. Scandinavian Journal of Public Health, 33(5), 370-375.

Westerlund, H., Alexanderson, K., Akerstedt, T. et al. (2008). Work-related sleep disturbances and sickness absence in the Swedish working population 19931999. Sleep, 31(8), 1169-1177. 